\title{
Assessing the Level of Awareness of Smart Building Technologies (SBTs) in the Developing Countries
}

\begin{abstract}
Purpose: The purpose of this paper is to investigate the awareness level of SBTs among construction professionals in developing countries such as Ghana, and identify the key factors that have the significant capability of influencing the awareness level significantly.
\end{abstract}

Methodology: Data was collected through questionnaire survey from 227 construction design team and project managers in the Ghanaian construction industry. Descriptive analysis and multivariate analysis using multiple regression were employed to analyse the data.

Findings: Averagely low level of SBTs awareness was observed to exist among professionals in the construction industry of Ghana. The study further revealed "training programs" by organizations and "individual knowledge" as the key factors capable of significantly influencing the level of SBTs awareness in the construction industry of developing countries, particularly Ghana.

Practical Implication: This paper identified training programs by organizations and individual knowledge as the two key factors having significant capability of influencing the SBTs awareness in the construction industry of developing countries such Ghana. The two factors can be incorporated in policy making process via considerations to help create SBTs awareness, such as encouragement of Continuous Professional Development (CPD) towards smart building concept in relation to construction sustainability.

Originality: This study conceptualizes from a systematic professional perspective and provides empirical evidence on the key significant factors capable of influencing the awareness of SBTs in the developing countries such as Ghana.

Keywords: Awareness level, building performance, construction industry, developing countries, Influencing factors, SBTs.

\section{Introduction}

The introduction of the SBT concept which also constitutes elements of Zero Energy Buildings (NZEB) concept (Harkouss et al., 2018) could be a measure in ensuring efficient energy consumption in buildings with regards to the previously addressed future projections on energy intensity increase (Nižetić et al., 2019). According to Takasolutions (2018), Smart buildings provide solutions, improve efficiency, reduce consumption and energy costs. Takasolution (ibid) added again that the use of sensors built into infrastructure and data collected in smart buildings allows for a significant improvement in the management of buildings. According to TrueOccupancy (2019), Smart buildings integrate technology and the Internet of things (IoT) to provide solutions to the age-old issues of overspend and inefficiency in building construction and use, including: reduce energy consumption, provide building efficiency, predictive maintenance, increase productivity and better use of resources. Smart buildings within a smart grid may not only participate to load shifting, increase energy efficiency or decrease in electricity consumption, but can also contribute significantly to the reduction of $\mathrm{CO}_{2}$ emissions (Wang and Moriarty, 2018). Buckman et al. (2014) made a point that Smart buildings are noted to be the future of the urban built environment, enabling more functionality from more constrained resources and more stringent building regulations. The idea of the smart home emanated from the concept of home automation, which provides benefits to the end-user including lower energy cost, provision of comfort, security and assistance to the everyone including the disabled (Pedrasa, 2010). According to Zhang et al. (2013), smart building is turning to be more attractive and viable in the building industry whilst meeting both the desire for comfort and energy saving. Also, smart building is seen as a building which totally controls its own environment (Buckman et al., 2014; Ogie et al., 2017). 
In developing countries, the number of new buildings is growing rapidly, and the energy prices and market often do not encourage the use of efficient technologies (Iwaro and Mwasha, 2010) to improve building performances. Developing countries are witnessing tremendous growth in their building stock, which is putting pressure on power and other energy systems (Evans et al., 2014), hence affecting building performances. Sarfo (2016) focused on environmentally sustainable construction process in Ghana by developing a structure that will drive and allow contractors to create adaptation capabilities for environmentally sustainable construction processes. Addy et al. (2017) worked on the implementation of a building energy efficiency evaluation method to measure the energy efficiency of offices in Ghana, but did not explicitly emphasize whether the emphasis was on smart building and thus provided inconclusive evidence. Gyamfi et al. (2018) also delved into the situation of Ghana's energy efficiency in the construction industry without recognizing the smart building concept among construction professionals. Few researchers: Addy et al. (2017), Sarfo (2016), Gyamfi (2018) and Chan et al. (2018) have touched and encouraged smart buildings in Ghana, in the context of energy efficiency without establishing the concept of smart building into the Ghanaian construction industry. In developing countries such as Nigeria, Ogunde et al. (2018) assessed the integration of building automation systems in residential in Nigeria and discovered that there is lack of awareness of building automation system (which is an integral part of smart buildings); and therefore recommended that there should be an enlightenment and training of construction professionals on the importance of smart buildings. Oyewole et al. (2019) then evaluated the awareness of smart building features and discovered that SBTs awareness is fair and almost half of the respondents were not aware of smart building features. In Ghana, Ahiabor (2019) claimed that there are clear opportunities to implement a smart building model, but for many organizations, deeper understanding of smart building technologies is needed. Construction professionals in Ghana are not fully trained towards smart building construction principles, and thus lack the know-how to properly execute and deliver smart building project. It is then noticeable that the concept of smart buildings has not been fully exploited due to lack of awareness and resources in Ghana. The paucity of conclusive evidence on SBTs adoption in the developing countries is largely attributed to lack of awareness and cognisance about smart building concept amongst the construction team players or professionals as a whole (Makarfi, 2015). This study, therefore, empirically investigates the awareness on SBTs and identifies the factors that can significantly influence the level of awareness among the construction professionals in developing countries, particularly Ghana. The result can provide an effective information to guide construction organizations in targeting their effort in full implementation of SBTs towards execution and delivery of smart building projects.

\section{Concept of Smart Building Technologies (SBTs)}

Smart building technology generally refers to the integration of four systems: A Building Automation System (BAS), a Telecommunications System (TS), an Office Automation System (OAS), and a Computer Aided Facility Management System (CAFMS) (Vattano, 2014). Vattano (2014) asserted that the home automation systems are driving interesting results related to the increase of efficiency, reduction of waste, accessibility, comfort, safety and making every node of an intelligent network, capable of sharing data and information with the outside world in an intelligent manner. Darby (2018) also asserted that Smart Building Technologies are integrated into building to achieve luxury with a class of efficiency. Home automation was then developed later due to the concept of automation and the services of using sensing and remote control (Darby, ibid).

Many organizations have placed huge amount of investment on technology systems to assist them in performing many different operations and tasks (Kashada et al., 2016). According to Kashada et al. (2016), adoption is considered in five phases, which include the awareness phase which involves the users or the individuals acquiring the information on the specific technology; the persuasion phase in which individuals become persuaded to adopt new technology; the decision stage in which the individuals make decision to adopt; the implementation stage in which technology is implemented by the party; and finally the confirmation stage in which the individual evaluate the actual outcomes of the specified technology and the expected outcomes. 
The study also relates to the theory of Intelligent Design (ID). With the advent of technology, our buildings are getting more and more responsive to human needs. Not only are the devices (automation/sensory based) making them easier to use and function, but also giving contemporary architecture an image of sophistication and high-tech look. "Understanding the concept of intelligent design and also realising that science is provisional, and is subjective to many influencing parameters; there is branch out from this point into the world of Architectural Design, and appreciate the disparity pronounced in the design created against that of nature" (Gilder and Clements-Croome, 2010). Gilder and Clements-Croome (ibid) believed that, with prevalent technology and systems, the idea of designing a building was made as reactive and receptive to humans. A building may therefore be regarded as a living organism harbouring its resident from outer environment. It then relies on systems such as Building Automation System (BAS), embedded sensors and actuators, Design Quality Indicator (DQI) etc. According to Gilder and Clements-Croome (2010), even though the complexity and Intelligent nature of smart buildings evolves from an intelligent cause, it is also envisioned with systems such as BAS, DQI, embedded sensors and actuators, etc. The theory helps to make known the systems that are put together to achieve the concept of smart building, therefore creating awareness on the SBTs. This study thus contributes to theory by adding to the existence of ID theory.

\section{Influencing Factors of Awareness Level of SBTs}

Technology adoption is the process that commences with the user and operator awareness of the technology, and finishes with embracement and full use of that technology (Renaud and Van Biljon, 2008). The level of awareness of the potential user or adopters of any technology has a direct influence on the adoption of the particular technology (Kashada et al., 2016). The level of awareness is also determined by various factors such as the availability of information. This study explored the factors that influence awareness, namely: "organizational context (training program) (Lin and Ho, 2011; Rahim and Musa,2018), environment (government regulation and policy) (Diabat and Govindan, 2011), and individual (Knowledge of the executive) (Mudgal et al.,2010)”.

\section{Organizational Context}

Organizations should develop awareness of SBTs to ensure that workers have basic understanding of SBTs. However, the use of smart practices may add complexity to the process and require a high level of learning and training (Lin and Ho, 2011). Due to this, an effective training programme should be developed by organization to help improve and impart knowledge of smart building practices among employees and suppliers (Sarkis, 2012).

\section{Environment}

According to Diabat and Govindan (2011), government regulations are significant drivers for the adoption of SBTs in the construction industry because of government legislation on sustainability. For example, the government has encouraged the adoption of information technology (IT) legislation that provides a framework for a low-carbon economy (Rahim and Musa, 2018). Again, political issues also give effect for the adoption of new necessary technologies whereby political pressure comes from government regulations (Molla and Abareshi, 2012).

\section{Individual}

Knowledge of SBTs has been a key factor in the adoption and implementation of SBTs. According to Renwick et al. (2013), a pro-environmental approach requires the knowledge and skills of employees to make significant contribution to the adoption and implementation of SBTs. Mudgal et al. (2010) 
argued that it is essential to achieve the desired environmental performance, skills and knowledge of employees because lack of knowledge leads to failures in the adoption and implementation of new technologies.

The study discovered that the status of adopting and implementing SBTs is challenging due to the low level of awareness and the lack of knowledge of its stakeholders such as Project Managers and other construction design teams. And factors such as training programmes, government regulations and policy and knowledge of the executives is capable of influencing positively the level of SBTs awareness. Zainul-Abidin (2010) also asserted that there is a long way to go to achieving sustainable construction industry, and this process needs an input from all industry stakeholders. Durdyev et al. (2018) argued that, despite the similarity in findings of studies on level of awareness of SBTs worldwide, the situation in each country, due to its sui generis socio-economic-politic context, requires a particular diagnosis. The intention of this survey-based research is to assess the level of awareness of SBTs by the construction professionals in developing countries such as Ghana, and identify the key factors capable of influencing significantly the level of SBTs awareness. It is hoped that the outcomes of this study enrich knowledge about the Smart Building Technologies in achieving its sustainability in developing countries and form a significant base for future sustainable construction works.

\section{Methodology}

From review of relevant literature, this study identified the key potential factors that are capable of influencing the level of awareness of SBTs in the construction industry of developing countries, as illustrated on Figure 1. For a research study by Rowlinson (1988), well known factors are more applicable because respondents will be able to respond easily. Cheng and $\mathrm{Li} \mathrm{(2002)}$ also asserted that, examining "well known factors" would be more useful for gaining a deeper understanding of the factors influencing the level of awareness of SBTs in developing countries.

\section{<Insert Figure 1 about here>}

The study adopted questionnaire survey (i.e. quantitative research strategy), which is a systematic method for gathering data on a sample, and known to be widely used in construction management researches (Huang et al., 2016). A questionnaire survey was conducted to investigate and identify the significant factors capable of influencing the level of awareness of SBTs in developing countries, particularly Ghana. Prior to the survey, a pilot survey was conducted to test the comprehensiveness and relevance of the questionnaire to help avoid ambiguities. The questionnaire was finalized based on the feedback from the pilot study. The study adopted the formula of Cochran to calculate the sample size for the study due to the unknown population size (Cochran, 1963) of the construction professionals in the 221 construction companies by adopting the formula, equation (1):

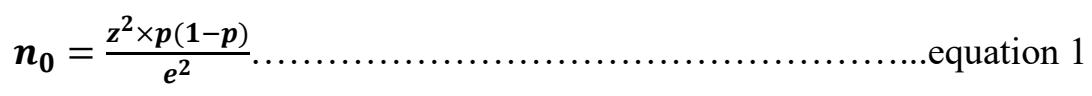

$\mathbf{n}_{\mathbf{0}}=$ Sample size, which needs to be estimated, $\mathbf{z}=$ Selected critical value of desired level of confidence or risk; 95\% confidence level (The value of $(1-\alpha)$ in Standard Normal Distribution z-table, which is 1.96 for $95 \%), \mathbf{p}=$ Estimated proportion of an attribute that is present in the population or maximum variability of the population; $50 \%$ variability of the population (which is maximum), $\mathbf{e}=$ Desired level of precision or margin of error; $5 \%$ margin of error.

$$
n_{0}=\frac{(1.96)^{2} \times 0.5(1-0.5)}{(0.05)^{2}}=384.16
$$


The study employed sample size of 385 due to the unknown population size of all the construction professionals (project managers and construction design teams) among the 221 construction companies in Ghana. Also, the study employed purposive sampling to help collect data from project managers and the construction design team of construction firms who are known to possess specific characteristics (ability to come-out with design, ensure feasibility of design, ability to delegate task, prioritizing activities on smart project, etc.), as well as convenience sampling which is quick, inexpensive and convenient, due to the limited time needed to conduct the study. The questionnaires were then distributed through email to the carefully selected respondents including the Project Manager, Electrical Engineer, Architect, Quantity Surveyor, Structural Engineer, Mechanical Engineer, Construction Manager, Service Engineer, Planner and IT Specialist in licensed D1, D2, D3 and D4 classes of construction companies in Greater Accra and Kumasi, Ghana (Ahadzie, 2007). These classes of construction companies all have the financial standing capability and the required skills for executing and delivering smart building projects. The respondents were asked to rank the influencing factors based on the five-point Likert scale: 1=Not Significant; 2=Less Significant; $3=$ Moderate; 4=Significant; 5=Very Significant. The study again sought to determine the level of awareness of SBTs in the construction industry by requesting the respondents to rate their level of awareness based on: $1=$ Very Low, $2=$ Low, $3=$ Moderate, $4=$ High and 5=Very High. The study sought protect the privacy of the respondent by a strict standard of anonymity, and also the assurance that the research is for academic purposes. The total number of questionnaires retrieved were 227, making a response rate of $58.96 \%$ of the sample size of 385 . The study approved the $58.96 \%$ for further analysis because Mellahi and Harris (2016) declared that the acceptable rate of survey responses ranges between $50 \%$ and $70 \%$.

\section{Data Analysis}

Cronbach's Alpha coefficient was adopted to check the reliability and consistency under the adopted scale of measurement, ranging from 0 to 1 , where 1 is the highest level of validity and reliability of quantitative inputs. Norušis (2011) asserted the threshold for Cronbach's Alpha to be 0.7, after which further analysis can be done. From the test, the Cronbach's Alpha for the scale was 0.934. The study sought to ask questions to help assess the level of awareness on the use of SBTs in developing countries. The scale for measuring the outcome of the questions achieved a Cronbach's Alpha of 0.902. The result then portrays that further analysis can be run using the adopted scale of measurement. Frequency was espoused to determine the level of awareness of SBTs in the construction industry. Again, cross-tabulation was adopted to test the distributed responses on the awareness question (YES/NO) as shown on Table 1. The mean score was then used to determine the central trend of the influential factors whilst the standard deviation was employed to measure the degree of variability on the factors, as illustrated on Table 2. Multiple regression analysis was finally adopted to examine whether there is a significant relationship between the identified factors (Independent variable) and the level of awareness of SBTs (dependent variable), as indicated on Table 2.

\section{Survey Result}

\section{Background Analysis of Respondents}

To increase the credibility and reliability of the result, this section described the background of the respondents based on the data gathered, by considering the academic qualification and experience of professional.

According to Hegarty et al. (2011), good academic qualification can help to gain more knowledge for professional development and building critical thinking model. Hence, the study considered Higher National Diploma (HND), Bachelor of Science (BSc), Masters of Science/Philosophy (MPhil), Doctor of Philosophy $(\mathrm{PhD})$ and any other. The background analysis denoted the result as $\mathrm{PhD}$ frequency $(f)$ 
$=17$, MPhil $f=83$, BSc $f=93$ and HND $f=33$. It also showed that only 1 respondent chose other, which could possibly mean the participant works with certificate earned in the academia. The result, therefore, depicts that out of the 227 respondents who responded to the questionnaire, majority have an academic background of BSc and only 1 with a certificate, which is unknown. This then portrays that the respondents are academically inclined in responding to the questionnaire in the area of construction management, therefore increasing the credibility of the information and study result.

Ascertaining the working experience of the respondent is very important, as it also contributes to the credibility of information given by the respondents. According to DeRue (2009), work experience has been perceived to guarantee for both quality and quantity in performing a specific task. Drawing conclusion from the background analysis, 92 respondents have work experience of 5-10 years, followed by 'less than 5 years' $f=84$ respondents; ' $11-15$ years' $f=39$; ' $16-20$ years' $f=10$; and ' $\geq$ 20 years' $f=2$. The result depicts that the respondents have experience in the construction industry, and are capable of making decision towards the SBTs adoption. Also, the idea of smart building seems to be current, and therefore, its adoption can relate properly with the respondents with work experience below 15 years.

\section{Level of Awareness of SBTs in developing countries}

The study investigated the SBTs awareness among the construction professionals in Ghana by determining awareness level using frequency $(f)$ in a form of bar graph, as illustrated on Figure 2. The finding showed that, the respondents with moderate level of awareness were 106; high level of awareness were 76; low level of awareness were 39; very high level of awareness were 4 and very low level of awareness were 2 . The analysis showed that the majority $(f$ 'moderate' $=106)$ of the professionals who responded to the structured questionnaire in relation to the level of SBTs awareness have moderate level of SBTs awareness. Meanwhile, for the purpose of adopting SBTs, it is good to have construction professionals having high level of SBTs awareness. From Figure 2, construction professionals with 'very low' level to 'moderate' level of SBTs awareness put together (i.e. 'moderate' $f=106$; 'low' $f=39$ and 'very low' $f=2$ ) are more than the professionals with 'high' level to 'very high' level of SBTs awareness combined (i.e. 'high' $f=76$; and 'very high' $f=4$ ). To conclude, construction professionals in the Ghanaian construction industry are observed to have averagely low level of SBTs awareness (i.e. 'moderate' $f=106$; "low' $f=39$ and 'very low' $f=2$ ); hence, the awareness of SBTs is not sufficient and still needs to be enhanced. Therefore, there is a need to create awareness of SBTs and its practices to construction professionals/employees which can increase their level of knowledge on SBTs (Azmi et al., 2017ab; Rahim and Musa, 2018). The study further examined the level of awareness by requesting the respondents to answer the questions, as shown on Table 1.

\section{<Insert Figure 2 about here>}

From Table 1, Question 1 was "Have you heard of Smart Building before?": there were 227 responses for this question, of which 202 out of 227 said yes. This shows that most of the respondents have heard of SBTs. Question 2 was "Did you know about Smart Building before this questionnaire?": Among the 227 respondents to this question, 167 respondents knew about SBTs before the questionnaire survey. The result, therefore, depicts that most of the respondents knew SBTs before the survey study. Question 3 also surfaced that 118 respondents knew the application of SBTs based on the question: "Do you know the application of SBTs?". As was addressed through the question 4, 124 respondents did not have idea on how the SBTs works, i.e. the technical aspect of SBTs. This indicates that there are a smaller number of professionals who know the technical aspect of SBTs. 
Question 5 extracted that majority of the respondents (172 out of 227) are aware of the main benefits of SBTs based on the question: “Are you aware of the main benefits of SBTs?". In answering question 6, 148 out of 227 respondents are aware of what SBTs can bring to the construction industry. Question 7 posited that 148 out of 227 respondents are aware that SBTs is capable of enabling sustainability in construction. Based on question 8, 122 out of 227 respondents do not have any idea of the cost SBTs, therefore, being the majority in the construction industry in Ghana. The response to question 9 posited that, 129 out of 227 respondents in the construction industry do not have idea about the need for initial investment to kick-start or begin SBTs, representing most of the construction professionals. In relation to "question 10", 169 out of the 227 respondents believe that the implementation of SBTs in the construction industry would pay off. Although not all the respondents responded yes to the question 10 , but response certainly points to a positive indication by project managers and construction managers in Ghana that adopting/implementing SBTs would pay off.

The response to question 11 indicated a broad consensus by the respondents on the requirement for training on the technologies for implementing SBTs with 169 out 227 "yes" responses from the research participants. Question 12 depicted that 164 out of 227 respondents consider that SBTs gives more benefits than barriers in the construction industry. With response to question "13", 165 out of 227 the respondents agree to change from conventional method to SBTs if they are given the chance and support. Also, the results from question 14 indicated that 128 out of 227 respondents have not attended any talk or seminar on SBTs. This then proves to the fact that, there need to be creation of awareness of SBTs in the Ghanaian construction industry. With respect to contribution, question 15 indicated that 170 out 227 respondents agreed that SBTs contributes to "future of project information management", and there needs to be adopted/implemented. Question 16 indicated that 183 out of 227 respondents suggested the need for SBTs adoption in Ghana. The study then proves the fact that, developing countries such as Ghana needs to adopt SBTs.

\section{<Insert Table 1 about here>}

\section{Influence-Awareness Factors}

The study adopted regression analysis to determine the significant relationship of the influencing factors towards the awareness of SBTs. From Table 2, the mean score analysis indicated that "Organizational context (training program)" (mean=4.29) and "Individual (Knowledge of the executive)" (mean=4.29) are the two main factors prioritized to influence the level of awareness of SBTs in developing countries, whereas "Environment (government regulation and policy)" (mean=4.27) was found to be the factor to have the least influence on the level of SBTs awareness. The study again adopted standard deviation to report on the consistency in agreement among the project managers and the construction design teams. Steven (2012) asserted that a standard deviation of less than 1.0 indicates consistency in agreement among the respondents of the reported level of response. Therefore, the result of the study shows consistency in agreement on the factors; Organizational context (training program)" (standard deviation=0.919), "Individual (Knowledge of the executive)" (standard deviation=0.913) and "Environment (government regulation and policy)" (standard deviation=0.900). The finding shows that "Organizational context (training program)" and "Individual (Knowledge of the executive)" are the key factors that are capable of influencing the level of awareness of SBTs in developing countries. The outcome is consistent with study by Renwick et al. (2013), when asserted that knowledge and skills of employees are requirement to make a significant contribution to the adoption and implementation of new technologies, such as SBTs. Training programs and knowledge of individuals have been regarded as the significant factors capable of influencing the adoption and implementation of innovative technologies by Mudgal et al. (2010), Lin and Ho (2011), Sarkis (2012) and Rahim and Musa (2018). This, then, depicts that the organizations, as well as practitioners and policy makers in Ghana can rely on "training programs" such as Continuous Professional Development (CPD) to enhance individual workers'/professionals" knowledge on the awareness of SBTs. 
The study identified the three factors (i.e. Organizational context (training program), Individual (Knowledge of the executive) and Environment (government regulation and policy)) to be contributing to the level of SBTs awareness in the construction industry, but their significant influences were as a result of their p-value. According to Frost (2019), p-values and coefficients in regression analysis work together to inform which relationships in your model are statistically significant and the nature of those relationships. Frost (2019) asserted that the p-values help to determine whether the relationships that you are observing also exist in a larger population. From Table 2, the study identified "Environment (government regulation and policy)" as being statistically insignificant in influencing the level of awareness of SBTs (P-value greater 0.05). Again, the study discovered that "Organizational context (training program)" and "Individual (Knowledge of the executive)" are statistically significant in influencing the level of awareness of SBTs in the construction industry ( $\mathrm{p}$-value less than 0.05), which is consistent with the studies by Azmi et al. (2017ab) and Rahim and Musa (2018), as illustrated on Figure 3. This then proved to the fact that "Organizational context (training program)" and "Individual (Knowledge of the executive)" were prioritized equally to be capable of influencing the level of SBTs awareness in developing countries based on mean score ranking.

\author{
<Insert Table 2 about here> \\ <Insert Figure 3 about here>
}

\title{
Discussion
}

The key significant factors revealed by the study are in line with the findings of previous studies (e.g. Renaud and Van Billion, 2006; Mudgal et al., 2010; Renwick et al., 2013; Azmi et al., 2017ab; Ogunde et al., 2018; Rahim and Musa, 2018; Oyewole et al., 2019). The analysis on the significant interrelationship between the influencing factors and the level of awareness of SBTs derived two key factors namely; "training programs" and "individual knowledge", which popped out to be the key significant factors capable of influencing the SBTs awareness level. The finding implied that there is averagely low level of SBTs awareness among the construction professionals in Ghana, and therefore, needs to be increased, as the smart building concept in Ghana is new, and globally emerging. Also, majority responded that they have had no talks with regards to SBTs, but they feel the need to adopt because SBTs are known to improve building performances. Buildings integrated with SBTs could ensure efficient energy consumption, provision of comfort, security and assistance to the disabled (Pedrasa, 2010; Takasolutions, 2018; Nižetić et al., 2019). Programs, such as CPD and workshops are very necessary in creating SBTs awareness if encouraged and geared towards the concept of smart buildings, hence increasing the individual knowledge on SBTs in the construction industry. Training programs and individual knowledge are joint forces capable of increasing the level of SBTs awareness among professionals because training programs directed to smart building concept has the propensity to increase the knowledge of the professionals towards SBTs (Lin and Ho, 2011; Sarkis, 2012; Kashada et al., 2016)

\section{Conclusion}

The study has investigated the awareness level of SBTs in developing countries, specifically Ghana, and identified the significant factors capable of influencing the SBTs awareness. Averagely low level of SBTs awareness was observed to exist among the construction professionals in Ghana, and they feel for the need to adopt SBTs because smart buildings are known to be energy efficient, comfortable, secured and assist the disabled. The paper concludes that the SBTs awareness of developing countries such as Ghana is influenced significantly by training programs and individual knowledge. From a systematic perspective of construction professionals in developing countries, the 
key influencing factors, which may help to increase the SBTs awareness level include encouraging training programs such as CPD towards smart building concept, which will add up to the knowledge of individuals in relation to building performances and construction sustainability.

\section{Contribution}

\section{Practical Contribution}

The distinction about this study lies on the notion of offering construction professionals in developing countries such as Ghana new insight related to the factors that influence the SBTs awareness. The insight is; to increase the SBTs awareness level among construction professionals, organizations must encourage training programs such as workshops and CPDs in relations to smart building concept to help increase the individual knowledge of employees on SBTs. The study also makes clear the significant key factors that need to be incorporated in policy making processes to help create awareness of SBTs in developing countries.

\section{Theoretical Contribution}

The findings of this study show the perception of construction professionals in developing countries on SBTs. SBTs awareness is very crucial for executing and delivering smart building project. Further, this study is the first endeavour devoted to test the model of factors capable of influencing the SBTs awareness in the construction sector of Ghana. This study is thought to have a reasonable contribution to the professional behaviour literature towards smart building concept through developing and testing a model of factors (organizational training programs, environment and individual knowledge) that have the capability of influencing SBTs awareness in an emerging business and construction sector economy, Ghana

\section{Managerial Implication}

CEOS of construction firms can plan and execute smart building projects to help increase the awareness of SBTs among employees/professionals. This would influence the familiarity of profession in relation to smart building concept. The study also indicates that training programs when encouraged in organizations is capable of increasing SBTs awareness among construction professionals towards execution and delivery of smart building projects.

\section{Recommendation}

The finding revealed the level of SBTs awareness among the construction professionals in Ghana to be averagely high, and suggested that holistic strategies that must be formulated to help increase the awareness systematically. To highlight, training programs can be encouraged to help boost individual understanding and knowledge of smart building including its benefits through CPD and other relevant workshops. Labour/employee training should strategically focus on upgrading technological competence of the workforce in the construction industry. Smart and sustainable construction should be promoted by more integrated policy incentives and regulatory guidance and facilities by better project collaboration and management among the construction professionals.

\section{Limitations and Future Studies}

With regards to research limitation, the study identifies theoretical and methodological limitations which warrant further future research. In relation to theoretical limitation, the study examined three main factors that are capable of influencing the SBTs awareness in developing countries, particularly Ghana. Future research needs to investigate other factors that might influence the SBTs awareness among construction professionals in developing countries. Training programs and individual knowledge evolved as the key significant factors capable of influencing the SBTs awareness in 
developing countries; therefore, future work can use qualitative research to investigate the real impact of the SBTs awareness among construction professionals. From a methodological standpoint, the necessary data were collected from construction professionals or expert having experience in promoting SBTs in the construction industry of Ghana. The findings of the study are based on data from Ghana but not from other developing countries. This does not limit the generalizability of the study, since the research aimed on quality of response rather than quantity. The findings can serve as a lesson, and extrapolated to other developing countries, even though the study was limited to Ghana. The generalizability of the findings could be improved by further research into a wider context. For instance, because of the different nature of every country, the future research work should consider the level of awareness of SBTs, as well as influencing factors in different developing countries. Also, it is recommended to establish energy models that will help to measure the SBTs adoption and implementation in developing countries.

\section{Reference}

Addy, N. M., Adinyira, E. and Joshua, A., (2017). Developing a Building Energy Efficiency Assessment Tool for Office Buildings in Ghana: Delphic Consultation Approach. Energy Procedia, 111, pp.629-638.

Ahadzie, D. K., (2007), "A Model for Predicating the Performance of Project Managers in Mass House Building Projects in Ghana", Published PhD Thesis, University of Wolverhampton, UK.

Ahiabor, G., (2019), Smart buildings are coming: But who holds the keys? https://www.graphic.com.gh/news/general-news/smart-buildings-are-coming-but-who-holdsthe-keys.html, Accessed: 17/08/2019.

Azmi F. R., Musa H., and Shahbodin F., (2017a). Implementation of green human resource management in Malaysia. In Proceedings of Mechanical Engineering Research Day, pp. 257258.

Azmi FR, Musa H, and Abdullah AR, (2017b). Analysing the awareness of green technology in Malaysia practices, in Proceedings of Mechanical Engineering Research Day, pp.252-254.

Buckman, A.H., Mayfield, M. and BM Beck, S., (2014). What is a smart building? Smart and Sustainable Built Environment, 3(2), pp. 92-109, https://doi.org/10.1108/SASBE-01-2014$\underline{0003}$.

Chan, A.P.C., Darko, A., Olanipekun, A.O. and Ameyaw, E.E., (2018). Critical barriers to green building technologies adoption in developing countries: The case of Ghana. Journal of cleaner production, 172, pp.1067-1079.

Cheng, E.W.L., Li, H., (2002). Construction partnering process and associated critical success factors: quantitative investigation, Manag. Eng. 18 (4), pp. 194-202.

Cochran, W. G. (1963). Sampling Techniques, 2nd Ed., New York: John Wiley and Sons, Inc.

Darby, S.J., (2018). Smart technology in the home: time for more clarity. Building Research \& Information, 46(1), pp.140-147.

DeRue, D.S., (2009). Quantity or quality? Work experience as a predictor of MBA student success. GMAC Research Reports RR-09, 9.

Diabat A and Govindan K. (2011), An analysis of the drivers affecting the implementation of green supply chain management, Resource Conservation Recycle; 55 (6): pp.659-667.

Durdyev, S., Zavadskas, E., Thurnell, D., Banaitis, A. and Ihtiyar, A., (2018). Sustainable construction industry in Cambodia: Awareness, drivers and barriers. Sustainability, 10(2), pp.392.

Evans, M., Halverson, M., Delgado, A. and Yu, S., (2014). Building energy code compliance in developing countries: the potential role of outcomes-based codes in India. In the Proceedings of the ACEEE Summer Study on Energy Efficiency in Buildings (pp. 8-61). 
Frost J. (2019), How to Interpret P-values and Coefficients in Regression Analysis, Statistics By Jim, https://statisticsbyjim.com/regression/interpret-coefficients-p-values-regression/, Accessed: $18 / 02 / 2020$.

Gilder, J. and Clements-Croome, D.J., (2010), May. Bio inspired intelligent design for the future of buildings. In Building a Better World: CIB World Congress.

Gyamfi, S., Diawuo, F.A., Kumi, E.N., Sika, F. and Modjinou, M., (2018). The energy efficiency situation in Ghana. Renewable and Sustainable Energy Reviews, 82, pp.1415-1423, https://doi.org/10.1016/j.rser.2017.05.007.

Harkouss, F., Fardoun, F., and Biwole, P.H., (2018). Optimization approaches and climates investigations in NZEB: A review. Building Simulation, 11(5), pp. 923-952, https://doi.org/10.1007/s12273-018-0448-6.

Hegarty, P.M., Kelly, H.A. and Walsh, A., (2011). Reflection in a workplace qualification: challenges and benefits. Journal of Workplace Learning, 23(8), pp.1366-5626. https://doi.org/10.1108/13665621111174889.

Huang, B., Mauerhofer, V., Geng, Y., (2016). Analysis of existing building energy saving policies in Japan and China, Journal of Cleaner Production, 112, pp.1510-1518.

Iwaro, J. and Mwasha, A., (2010). A review of building energy regulation and policy for energy conservation in developing countries. Energy Policy, 38(12), pp.7744-7755.

Kashada, A., Li, H. and Kashadah, O., (2016). The impact of user awareness on successful adoption of decision support System DSS in Developing Countries: THE Context of Libyan Higher Education Ministry. American Scientific Research Journal for Engineering, Technology, and Sciences (ASRJETS), 16(1), pp.334-345.

Lin C. Y. and Ho Y. H. (2011), Determinants of Green Practice Adoption for Logistics Companies in China, J. Bus Ethics;98(1), pp.67-83.

Makarfi, Z., (2015), An Assessment of The Level of Awareness of Intelligent Buildings Amongst Nigerian Architects (A Case Study of Kaduna Metropolitan Area), Department of Architecture, Faculty of Environmental Design, Ahmadu Bello University, Zaria, Undergraduate Thesis.

Mellahi, K. and Harris, L.C., (2016). Response rates in business and management research: An overview of current practice and suggestions for future direction. British Journal of Management, 27(2), pp.426-437.

Molla A and Abareshi A. (2012), Organizational green motivations for information technology: Empirical study, Journal of Computer Information System, 52(3), pp.92-102.

Mudgal RK, Shankar R, Talib P, (2010). Modelling the barriers of green supply chain practices: An Indian perspective, Int. J. Logist. Syst. Manag, 7(1), pp.81-107

Nižetić, S., Djilali, N., Papadopoulos, A. and Rodrigues, J.J., (2019). Smart technologies for promotion of energy efficiency, utilization of sustainable resources and waste management. Journal of Cleaner Production, https://doi:10.1016/j.jclepro.2019.04.397.

Norušis, M.J., (2011). IBM SPSS statistics 19 guide to data analysis. Upper Saddle River, New Jersey: Prentice Hall.

Ogie, R. I., Perez, P. and Dignum, V., (2017). Smart infrastructure: an emerging frontier for multidisciplinary research. Proceedings of the Institution of Civil Engineers: Smart $\begin{array}{llll}\text { Infrastructure and } \quad \text { Construction, } 170 \text { (1), 8-16, } & \text {, }\end{array}$ http://ro.uow.edu.au/cgi/viewcontent.cgi?article $=1248 \&$ context=smartpapers .

Ogunde, A., Emmanuel, I., Nduka, D., Ayedun, C.A. and Ogunde, A., 2018. Assessment of Integration of Building Automation Systems in Residential Buildings in Developing Countries: Professionals perspectives. International Journal of Civil Engineering and Technology, 9(6), pp.577-585.

Oyewole, M.O., Araloyin, F.M. and Oyewole, P.T., 2019. Residents' Awareness and Aspiration for Smart Building Features: The Case of Okota, Lagos, Nigeria. Nigerian Journal of Environmental Sciences and Technology (NIJEST), 3(1), pp.30-40.

Pedrasa M. A. A., (2010). Spooner TD, McGill IF. Coordinated scheduling of residential distributed energy resources to optimize smart home energy services. IEEE Trans Smart Grid; (1), pp. 134-43, https://ieeexplore.iee.org/abstract/document/5524053/. 
Rahim, F. and Musa, H., (2018), Green technology awareness: A case of Malaysia, Environment and Social Psychology, 3(1), pp.1-5.

Renaud, K. and Van Biljon, J., (2008), Predicting technology acceptance and adoption by the elderly: a qualitative study. In Proceedings of the 2008 annual research conference of the South African Institute of Computer Scientists and Information Technologists on IT research in developing countries: riding the wave of technology (pp. 210-219). ACM.

Renwick D. W S., Redman T, and Maguire S. (2013), Green Human Resource Management: A Review and Research Agenda, Int. J. Manag. Rev., 15(1), pp.1-14.

Rowlinson, S.M., (1988). An Analysis of Factors Affecting Project Performance in Industrial Building. Ph.D thesis, Brunel Univ., Middlesex, U.K.

Sarfo, M., (2016), Contractor's adaptation to the environmentally sustainable construction process in Ghana, Department of Construction Technology and Management, Kwame Nkrumah University of Science and Technology, Doctoral Dissertation, http://ir.knust.edu.gh/bitstream/123456789/10456/1/Sarfo_Thesis_final\%20submission.pdf.

Sarkis J. A, (2012), Boundaries and Flows Perspective of Green Supply Chain Management, Supply Chain Management an Int. J., 17(2), pp.202-21.

Stevens, J.P., (2012). Applied multivariate statistics for the social sciences. Routledge.

Takasolutions (2018), Advantages of Owning A Smart Building, https://takasolutions.com/blog/advantages-of-owning-a-smart-building/, $\quad$ Accessed: $22 / 08 / 2019$.

TrueOccupancy (2019), 5 Key Benefits of Smart Buildings, https://www.trueoccupancy.com/blog/5key-benefits-of-smart-buildings, Accessed: 22/08/2019.

Vattano, S., (2014). Smart Buildings for A Sustainable Development. Journal of Economics World, 2 , pp.310-324.

Wang, S.J. and Moriarty, P., (2018). Big Data for Urban Energy Reductions. In Big Data for Urban Sustainability, pp. 105-118, Springer, Cham.

Zainul-Abidin, N. (2010), Investigating the awareness and application of sustainable construction concept by Malaysian developers. Habitat Int., 34, pp.421-426.

Zhang, D., Shah, N. and Papageorgiou, L.G., (2013). Efficient energy consumption and operation management in a smart building with micro-grid. Energy Conversion and Management, 74, pp. 209-222. 


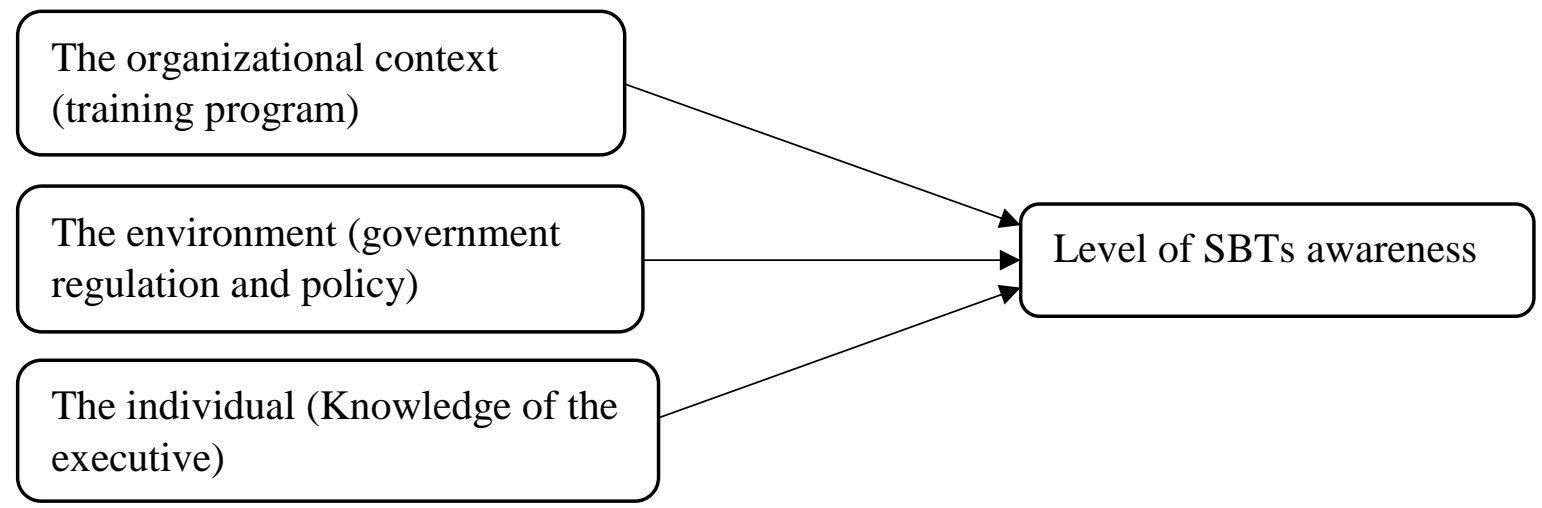

Figure 1: Key Potential Factors Influencing the level of awareness of Smart Building Technologies (SBTs)

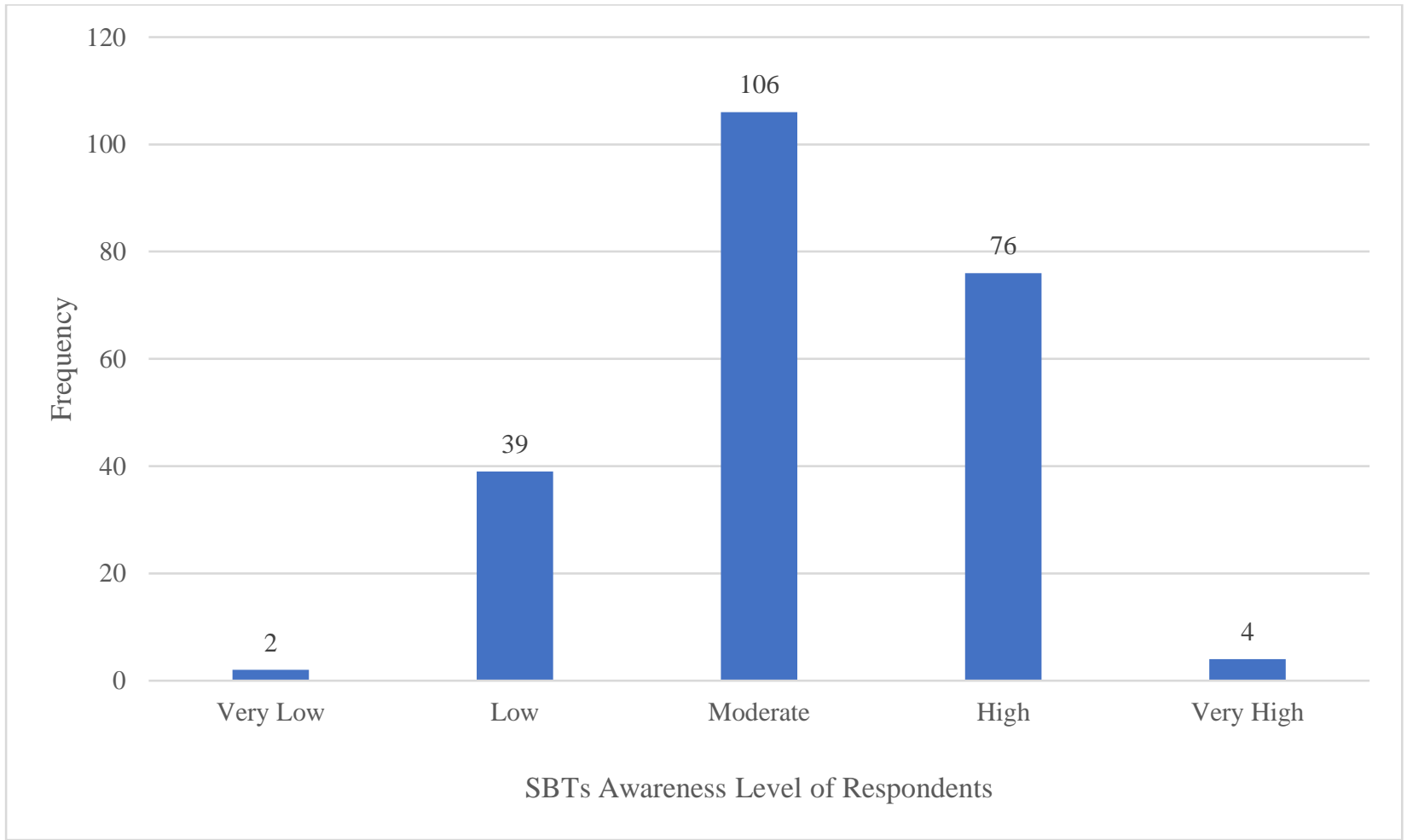

Figure 2: Frequency-Based Bar Graph Indicating the SBTs Awareness Level of the Respondents 


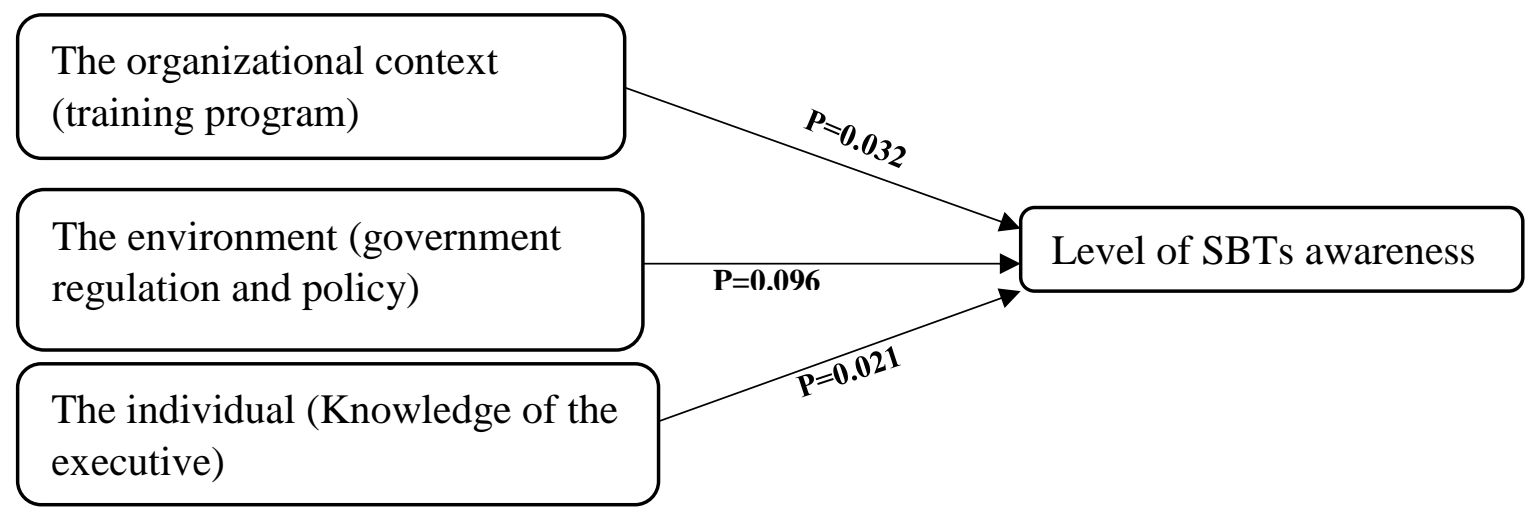

Figure 3: Factors Significantly Influencing the Level of Awareness of SBTs Based on Significant Level (Plevel) from Multiple Regression Analysis. 
Table 1: Crosstabulation Showing Summary of Responses (Yes/No) Showing Awareness to Adopt SBTs

\begin{tabular}{|c|c|c|c|c|c|c|c|c|c|c|c|c|c|c|c|c|c|c|c|c|c|c|c|c|}
\hline \multirow{2}{*}{ Code } & \multirow[t]{2}{*}{ Question } & \multicolumn{2}{|c|}{$\mathbf{P M}$} & \multicolumn{2}{|c|}{$\mathbf{E E}$} & \multicolumn{2}{|l|}{$\mathbf{A}$} & \multicolumn{2}{|l|}{ QS } & \multicolumn{2}{|c|}{$\mathbf{S E}$} & \multicolumn{2}{|c|}{ ME } & \multicolumn{2}{|c|}{$\mathbf{C M}$} & \multicolumn{2}{|c|}{$\mathbf{S e E}$} & \multicolumn{2}{|l|}{$\mathbf{P}$} & \multicolumn{2}{|l|}{ IS } & \multicolumn{3}{|l|}{$\mathbf{F}$} \\
\hline & & $\mathbf{Y}$ & $\mathbf{N}$ & $\mathbf{Y}$ & $\mathbf{N}$ & $\mathbf{Y}$ & $\mathbf{N}$ & $\mathbf{Y}$ & $\mathbf{N}$ & $\mathbf{Y}$ & $\mathbf{N}$ & $\mathbf{Y}$ & $\mathbf{N}$ & $\mathbf{Y}$ & $\mathbf{N}$ & $\mathbf{Y}$ & $\mathbf{N}$ & $\mathbf{Y}$ & $\mathbf{N}$ & $\mathbf{Y}$ & $\mathbf{N}$ & $\mathbf{Y}$ & $\mathbf{N}$ & Total \\
\hline$\overline{\mathrm{Q} 1}$ & $\begin{array}{l}\text { Have you heard of Smart Building } \\
\text { before? (Only hearing, not } \\
\text { knowing what is it) }\end{array}$ & 33 & 3 & 11 & 4 & 19 & 1 & 47 & 7 & 12 & 2 & 13 & 1 & 35 & 2 & 11 & 0 & 10 & 4 & 11 & 1 & 202 & 25 & 227 \\
\hline $\mathrm{Q} 2$ & $\begin{array}{l}\text { Did you know about Smart } \\
\text { Building before this } \\
\text { questionnaire? }\end{array}$ & 27 & 9 & 9 & 6 & 12 & 8 & 43 & 11 & 9 & 5 & 10 & 4 & 29 & 8 & 9 & 2 & 9 & 5 & 10 & 2 & 167 & 60 & 227 \\
\hline Q3 & $\begin{array}{l}\text { Do you know the application of } \\
\text { Smart Building Technologies } \\
\text { (SBTs)? }\end{array}$ & 20 & 16 & 6 & 9 & 10 & 10 & 28 & 26 & 5 & 9 & 4 & 10 & 20 & 17 & 9 & 2 & 8 & 6 & 8 & 4 & 118 & 109 & 227 \\
\hline Q4 & $\begin{array}{l}\text { Do you have any idea how SBTS } \\
\text { works? (Technical aspect) }\end{array}$ & 13 & 23 & 8 & 7 & 8 & 12 & 23 & 31 & 5 & 9 & 5 & 9 & 21 & 16 & 8 & 3 & 6 & 8 & 6 & 6 & 103 & 124 & 227 \\
\hline Q5 & $\begin{array}{l}\text { Are you aware of the main } \\
\text { benefits of SBTs? }\end{array}$ & 29 & 7 & 9 & 6 & 14 & 6 & 38 & 16 & 6 & 8 & 12 & 2 & 30 & 7 & 11 & 0 & 12 & 2 & 11 & 1 & 172 & 55 & 227 \\
\hline Q6 & $\begin{array}{l}\text { Are you aware of what SBTs can } \\
\text { bring to construction project? }\end{array}$ & 24 & 12 & 6 & 9 & 11 & 9 & 35 & 19 & 7 & 7 & 9 & 5 & 28 & 9 & 11 & 0 & 9 & 5 & 8 & 4 & 148 & 79 & 227 \\
\hline Q7 & $\begin{array}{l}\text { Are you aware that SBTs helps to } \\
\text { enable sustainability in } \\
\text { construction? }\end{array}$ & 26 & 10 & 4 & 11 & 14 & 6 & 38 & 16 & 7 & 7 & 6 & 8 & 23 & 14 & 9 & 2 & 11 & 3 & 10 & 2 & 148 & 79 & 227 \\
\hline Q8 & $\begin{array}{l}\text { Do you have any idea of cost of } \\
\text { SBTs (e.g. high, acceptable, etc.)? }\end{array}$ & 17 & 19 & 5 & 10 & 8 & 12 & 24 & 30 & 5 & 9 & 5 & 9 & 18 & 19 & 8 & 3 & 8 & 6 & 7 & 5 & 105 & 122 & 227 \\
\hline Q9 & $\begin{array}{l}\text { Do you have any idea about initial } \\
\text { investment to kickstart SBTs? }\end{array}$ & 16 & 20 & 6 & 9 & 8 & 12 & 21 & 33 & 5 & 9 & 4 & 10 & 17 & 20 & 9 & 2 & 7 & 7 & 5 & 7 & 98 & 129 & 227 \\
\hline Q10 & $\begin{array}{l}\text { Do you think that the } \\
\text { implementation of SBTs in a } \\
\text { construction company would pay } \\
\text { off? }\end{array}$ & 28 & 8 & 8 & 7 & 15 & 5 & 39 & 15 & 5 & 9 & 11 & 3 & 30 & 7 & 10 & 1 & 9 & 5 & 9 & 3 & 164 & 63 & 227 \\
\hline Q11 & $\begin{array}{l}\text { Do you agree that implementing } \\
\text { SBTs requires hands on training } \\
\text { on the technologies? }\end{array}$ & 28 & 8 & 8 & 7 & 13 & 7 & 43 & 11 & 7 & 7 & 12 & 2 & 29 & 8 & 9 & 2 & 11 & 3 & 9 & 3 & 169 & 58 & 227 \\
\hline Q12 & $\begin{array}{l}\text { Does SBTs give more benefits } \\
\text { than barriers in the construction } \\
\text { industry? }\end{array}$ & 28 & 8 & 8 & 7 & 13 & 7 & 40 & 14 & 6 & 8 & 9 & 5 & 30 & 7 & 9 & 2 & 10 & 4 & 11 & 1 & 164 & 63 & 227 \\
\hline Q13 & Given the chance and support, & 28 & 8 & 7 & 8 & 15 & 5 & 42 & 12 & 8 & 6 & 8 & 6 & 27 & 9 & 10 & 1 & 10 & 4 & 10 & 2 & 165 & 62 & 227 \\
\hline
\end{tabular}




\begin{tabular}{|c|c|c|c|c|c|c|c|c|c|c|c|c|c|c|c|c|c|c|c|c|c|c|c|c|}
\hline & $\begin{array}{l}\text { will you change from } \\
\text { conventional method to SBTs? }\end{array}$ & & & & & & & & & & & & & & & & & & & & & & & \\
\hline Q14 & $\begin{array}{l}\text { Have you attended any talks on } \\
\text { SBTs in country? }\end{array}$ & 15 & 21 & 7 & 8 & 10 & 10 & 20 & 34 & 4 & 10 & 4 & 10 & 16 & 21 & 9 & 2 & 8 & 6 & 6 & 6 & 99 & 128 & 227 \\
\hline Q15 & $\begin{array}{l}\text { Do you agree that SBTs } \\
\text { contributes to "future of project } \\
\text { information management"? }\end{array}$ & 29 & 7 & 6 & 9 & 13 & 7 & 45 & 9 & 8 & 6 & 8 & 6 & 30 & 7 & 10 & 1 & 11 & 3 & 10 & 2 & 170 & 57 & 227 \\
\hline Q16 & $\begin{array}{l}\text { As a construction professional, do } \\
\text { you feel the need for SBTs? }\end{array}$ & 30 & 6 & 9 & 6 & 16 & 4 & 46 & 8 & 10 & 4 & 8 & 6 & 33 & 4 & 11 & 0 & 10 & 4 & 10 & 2 & 183 & 44 & 227 \\
\hline
\end{tabular}

PM=Project Manager, EE=Electrical Engineer, A=Architect, $Q S=$ Quantity Surveyor, SE=Structural Engineer, ME=Mechanical Engineer, CM=Construction Manager, SeE=Services Engineer, $P=P l a n n e r, ~ I S=I T$ Specialist, $N=$ No, Yes=Y, F=Frequency 
Table 2: Multiple Regression Analysis, Reliability Analysis, Mean Score and Standard Deviation

\begin{tabular}{|c|c|c|c|c|c|c|c|}
\hline Factors & Mean & $\begin{array}{l}\text { Standard } \\
\text { Deviation }\end{array}$ & $\begin{array}{l}\text { Unstandardized } \\
\text { B }\end{array}$ & $\begin{array}{l}\text { Standardized } \\
\text { Coefficient Beta }\end{array}$ & $\mathbf{T}$ & Sig. (p-value) & $\begin{array}{l}\text { Reliability } \\
\text { Analysis }\end{array}$ \\
\hline (Constant) & & & 2.313 & & 9.277 & 0.000 & \\
\hline $\begin{array}{l}\text { Organizational context } \\
\text { (training program) }\end{array}$ & 4.29 & 0.919 & -0.231 & -0.278 & -2.155 & 0.032 & 0.934 \\
\hline $\begin{array}{l}\text { Environment } \\
\text { (government regulation } \\
\text { and policy) }\end{array}$ & 4.27 & 0.900 & 0.201 & 0.237 & 1.673 & 0.096 & \\
\hline $\begin{array}{l}\text { Individual (Knowledge } \\
\text { of the executive) }\end{array}$ & 4.29 & 0.913 & 0.233 & 0.279 & 2.33 & 0.021 & \\
\hline
\end{tabular}

a. Dependent variable: Level of awareness on SBTs 
